\title{
Making Friends and Caring - Data From Integrated Sex Education
}

\author{
Ansa Ojanlatva ${ }^{1}$, Hanna Sassi $^{2}$, Jutta Miilumäki ${ }^{2}$ \\ ${ }^{1}$ University of Turku \\ ${ }^{2}$ University of Turku-Rauma
}

\begin{abstract}
The present study examined connections between building and maintaining future relationships, being able to look after themselves, and after others (3 outcome variables) with perceptions of 6th-graders about sex education topics covered at school (20 explanatory variables). The study utilized a convenience sample (N=108/118; 91.5\% response) from 4 schools at the Rauma School District in Finland; one school provided two classes of 6th graders, another provided one combined class of 5th and 6th graders. The students were 12.3 years of age (median 12 years). Boys and girls did not differ in their responses to outcome variables. They received adequate amounts of information for future purposes of being able to look after themselves $(n=98 / 102)$ or after others $(n=81 / 108)$ but less for the purposes of building and maintaining relationships $(n=53 / 103)$. The outcome variable of building and maintaining relationships was associated with tolerance and understanding of difference, showing of emotions, and dating.
\end{abstract}

(C) 2005 Californian Journal of Health Promotion. All rights reserved.

Keywords: caring, integrated, relationships, sex education

\section{Introduction}

Along with building and maintaining relationships, both looking after self and looking after others, in other words, being a caring person is at the core of personal communication. These three characteristics should be present in a program used to teach young people about sexual health needs and issues as well as about health compromising behaviors, or in considering what protection to provide. Caring is cited as a healthy relationship ingredient involved in keeping a balance between being together with others and being separate from them (Donnelly, 2003). It is a typical characteristic of those involved in service, teaching, and medical professions. Looking after another person will likely result in reciprocity as well, and thus, it gives the feeling of positive social support.

The context of nurturing interpersonal relationships implies features such as protection or empathy. In sex education, protection of a person has been thought to include, e.g., the identification and control of boundaries (Shearer, 2002). Shearer (2002) differentiated between protective behaviors (educational activities), protective factors (modifying variables of knowledge, values, and mutuality), and the concept of protection (outcome or process).

Empathy is involved in looking after another, and it is essential in dealing with sex and sexuality issues. Emotions, feelings, or sensations affiliated with the right brain are known to typify empathy, whereas most of the educational sessions use the left brain for cognitive processes. The cognitive empathy components involved with the knowledge and experience of the left brain include 1) an accurate assessment of emotions, 2) adoption of the role of the other person, 3) insightful viewpoint of the other person, and 4) communicating of the experience to another person (Kalliopuska, 1990). Sexuality in turn, first and foremost, is a form of active communication and interaction, and at least to some extent, involves intuition. Since $65 \%$ of human expression is considered to be other than verbal, and in so doing, involved with the right brain (Kalliopuska, 1990), the order of events in 
relation to school sex education may appear conflicting at times.

Health needs of young people differ from those of adults (Blackie et al., 1998), and similarly, sexual health needs of adolescents are different from those of adults. Adolescents deal with issues of learning to understand their own sexuality, making and keeping friends, developing personal values and choices for decision making purposes, and considering consequences of their own actions (e.g., Blackie et al., 1998). Having positive human relations is among the goals of many young people (Blackie et al., 1998), and much of education aspires to strengthen the goals in theory. Moral decision making entails that a person is responsive to the needs of others (Greenberg et al., 1993). A good person will attempt to find a way to help when someone is in need of assistance. School-related education may not be used to identify the one being helped and/or his/her helper. Sometimes love affairs or friendships end in spite of everything. Then there is a need to know how to bring these affairs to a closure graciously and respectfully.

Several health compromising behaviors originate in childhood or early adolescence (Rew \& Horner, 2003). When a person is young, teenage pregnancies, sexually transmitted infections, or becoming victims of sexual abuse are examples of consequences of risky sexual practices especially when under the influence of drugs or alcohol. Adults may find themselves in similar situations but then those situations are called by different names. There has not been much written about when it becomes proper for a young person to get involved in a sexual relationship (Stuart-Smith, 1996), although many would agree that early adolescence is simply too early. We know that sexual growth and development, maturation, and experimentation with life and issues fill up the daily lives of these youngsters. Identity development is not finished as yet and much of sexual identity as part of it needs to be structured. Stuart-Smith (1996) reiterated that the frontal lobe of the brain is not completely myelinated until the age of 14 or 15 . Consequently, cognitive immaturity could be one reason for the tendency of teenagers to avoid preventive action in spite of knowing the risks involved in compromising behaviors.

Parents are understandably concerned about their children's uncompromising behaviors, but communication about the issues with children is not easy. A recent study revealed that good relations with parents during childhood will contribute to a satisfying adult sex life (Ojanlatva et al., 2003); the age at which the beneficial development is to take place was not identified. Another study with adults (20-54 years of age) indicated, however, that one's own family members may not be the best support providers in matters of sex life (Ojanlatva et al., in press). A spouse or partner was the best support provider in sex life issues followed by friends particularly among women. Since teenagers and their parents do not always communicate well together, the existing bond with the peers of the young person could function as a good start for being caring towards another person. Stuart-Smith (1996) further noted that guidance in compromising behaviors would need to be presented in a way accessible to the young person's level of cognitive development.

A comprehensive view of sexuality that Dr. Mary Calderone emphasized (Bruess \& Greenberg, 2004) includes an assortment of often more than 20 topics within health education. In order for a sex education program to be effective, it should provide young people a number of opportunities to explore their own attitudes and feelings about health issues (Blackie et al., 1998). Sex education is initially meant to provide background and concepts of intimate behaviors in collective cultural and educational manner without a binding reference to specific personal behaviors - just as mathematics, reading, and writing are known to have general rather than personal goals. The rationale is that a solid foundation of sexology content is expected for general civilized behavior. Being comfortable with sexuality, understanding one's own role as a sexual person, and appreciating the need to participate in sexual policy issues (Bruess \& Greenberg, 2004) were recently cited as examples of such a quality. A person is not expected to use school math in a grocery store but having had it at school will 
help assess personal daily expenditures. The same logic is often used of the relationship between health or sex education and personal lives of individuals: one may not be expected to develop personal health issues at school, but it would not be forbidden to use the information to quit smoking or lose weight or to apply the principles to maintain a sexual wellness plan.

But then, should (or could) the school health or sex education program be more than just general education? Might a sex education program help promote sexual health and eventually alleviate risk behaviors? Blackie (1998) felt that young people need help in finding ways of making healthy choices. As an example, self-efficacy is a useful concept for pondering sex education issues. Contraceptive self-efficacy among women has been found to be different from that among men: women need to take more responsibility for their actions, whereas men need to refuse sex when contraceptive protection is not present (Van den Bossche \& Rubinson, 1998). For both, the understanding of a protective behavior or the principle of caring would be advised.

The present study examined connections between building and maintaining future relationships as well as personally being able to look after themselves and after others (3 outcome variables) with perceptions of 6th graders about sex education topics covered at school (20 explanatory variables).

\section{Methods}

The present study was based on cross sectional survey data from a convenience sample at the Rauma School District in Finland. For reasons of convenience, three individual schools (150300 students each) were chosen with cluster sampling from an urban setting, plus one school from a rural setting (less than 150 students). The total sample was intended to comprise 118 students but 10 students were absent from school during the day of assessment $(\mathrm{N}=108 ; 91.5 \%$ response).

The present study was part of a larger survey that used separate questionnaires for the assessment of student-teacher perceptions about existing sex education issues of a potential health science curriculum. At each school, the principal granted the permission for the survey process and arrangements were made with the home room teacher to complete the survey in May 2004. Two of the authors (JM \& HS) carried out the survey, illustrated examples of responding to it, and answered questions from the students. Each teacher remained in the class room during the survey, and when needed, gave the students tasks to do after they had filled in the responses (within $30 \mathrm{~min}$ ) so that those having completed their task early would not disturb the rest of the students.

\section{Questionnaire}

The responses to three outcome variables were asked with no/yes options (Table 1):

Table 1

Response to Three Outcome Variables With No/Yes Options on the Questionnaire

Do you feel that you have received adequate information as far as future needs are concerned in being able to:
1. look after yourself
2. look after others
No Yes
$(n=102)$
3. build and maintain relationships
No Yes
$(n=102)$
No Yes $(n=102)$

No statistically significant differences were evident in the outcome variables by gender $(n=108)$.
The explanatory variables of interest included perceptions about whether 20 topics were implemented in sex education $(n=107)$ when the 
students were in the fifth grade [puberty/ changes, increases in height/ weight, selfacceptance as is, fears of having to do with sexuality, menstruation, (nocturnal) emission, contraception, fertilization, pregnancy/ childbirth, sexually transmitted diseases/ AIDS, sexual minorities, tolerance and understanding of differences, sexual harassment and violence, human relations, infatuation, display of emotions, experiencing closeness, dating, ending a relationship, receiving/giving affection].

The original series of questions was pilot-tested and later analyzed for validity and reliability. Consistency in the measurement of the sex education topics (Q. 5 in the questionnaire) was obtained by calculating the total Cronbach's alpha (0.798) as well as by dividing 20 response alternatives into four sum variables and calculating Cronbach's alpha coefficients for each sum variable (biological 0.615, psychological 0.594, cultural 0.575, ethical 0.386); the outcome of the total sum was considered rather high (Miilumäki \& Sassi, 2004). These four categories were formed based on the dimensions of human sexuality (Bruess \& Greenberg, 1981; 1994).

The data of the present study were analyzed using cross tabulations with the Chi squared test and confirmed with Cramer's Values.

\section{Results}

A total of 108/118 students (56 boys, 52 girls) replied (91.5\% response). At the time of the assessment, most students (59\% of boys, $60 \%$ of girls) were a mean of 12.3 years of age (median 12 ); only four students were 11 years of age and the rest were 13-year-olds.

Of 102 responding students, 90 felt that they had received adequate information about looking after self. The proportion of "no" responses was so small that it was difficult to ascertain statistical significance. Only one relationship with content coverage (contraception) was initially statistically significant $(p=0.0375)$, but with the Fisher's exact test needing to be used in this case, the value turned out to be nonsignificant $(p=0.0520)$. Similarly, 81 of the responding 102 students felt that they had received adequate information about looking after others. None of the sex education topics were connected with the amount of information students had received about looking after others.

About a half of the responding 103 ( $n=53 ; 51 \%)$ students felt that they had received adequate information on building and maintaining relationships. Three issues (tolerance and understanding of difference with $\mathrm{p}=0.4777$; showing of emotions with $\mathrm{p}=0.0300$ ), dating with $\mathrm{p}=0.0314$ ) had connections with the outcome variable.

[Cramer's Values were 0.1951, 0.2138, and 0.2438 , respectively, indicating a moderately good connection.]

\section{Discussion}

Most students of the present study felt that they acquired enough information about being able to look after themselves as well as after others (two separate outcome variables). The characteristics of a caring person were not identified, and therefore, it is not known if the students perceived these concepts in the same way. No connection was evident between these two characteristics and 20 issues covered at school. The outcome variable of building and maintaining relationships received a less satisfying response from the students than the other two. It was connected with three issues not being taught at school adequately: tolerance and understanding of difference, showing of emotions, and dating.

The present study utilized cross sectional survey data from a convenience sample of 4 schools at the Rauma School District in Finland. The questionnaire was pilot-tested for validity purposes before surveying the 6th-graders in the school district $(\mathrm{N}=108)$. During the data analysis, the total Cronbach's alpha was used to illustrate consistency of 20 sex education topics, and it was high (0.798). As a limitation, the findings shall not be generalized to the total country, or even the region as a whole, in part because of the cluster sampling procedure used to obtain data. The outcome may be used to formulate hypotheses and research questions or to generate discussion on the topic, however. 
In the larger survey (Miilumäki \& Sassi, 2004), puberty-related biological issues (e.g., menstruations, nocturnal emissions) were covered by and large and desired by students; psychological, cultural, and ethical issues received less attention. Emotional issues that were the focal point of three associations of the present study received far less attention than was desirable. Students have been reporting need for discussion about issues such as emotions, responsibility, or autonomy (Nummelin, 2000). Need for information on dating has been discussed in many reports (e.g., Kontula \& Meriläinen, 1988; Nummelin, 2000). Topics of sexual minorities, understanding of differences, or ending a relationship were hardly touched at all in the larger survey (Miilumäki \& Sassi, 2004), although there probably was need for them. More than a decade ago already, it was observed that boys find it more difficult to accept homosexual relationships than girls do (Kontula, Rimpelä \& Ojanlatva, 1992).

Most students reported that the school had provided them with adequate background for the issues of being able look for oneself and others. These students gave the grade of $C(7.5 / 10)$ to sex education being taught in those schools (Miilumäki \& Sassi, 2004). One would expect at least $\mathrm{B}$ to be given to a program that provides a good foundation on knowledge in one's own life. It seems that either these youngsters were modest in their expectations or did not know what they were up to. The connection between expectations and learned content may yet to be established. In a study a decade ago, Finnish boys were unaware of the most likely time when a woman may get pregnant (Kontula, Rimpelä \& Ojanlatva, 1992). With a policy statement in February 1993, health education was reduced from a required subject to being covered as the school district saw fit. It is unlikely that the collective learning has improved since 1994.

A decade ago, a study concluded that sex education as it was known then in the Finnish basic school was taught to students who were too old for it (15-16-year-olds) and recommended that it should be taught when they are 12-13-year-olds (Kontula, Rimpelä \& Ojanlatva, 1992). This recommendation is now becoming a reality with integrated issues of sex education for the 5th grade level, at least on paper.

When sex education issues are not discussed, part of the reason has to do with those leading the discussion. Some teachers are men and others are women. Some are young and others are older. Although sexuality education was recently cited as being taught in 93\% of American schools (Landry et al., 2003 cited in Bruess \& Greenberg, 2004) teachers were "unprepared to teach anything except the most basic and 'safe' topics - anatomy, STIs, and pregnancy prevention” (Bruess \& Greenberg, 2004, p. 339). Young teachers often face such challenges in teaching sex education but those challenges should be met head on. Teachers should try out new content and methodology and not adapt to routines of older teachers. It is often mentioned that teachers represent the community they work for and they may be selected for having the same qualities as the community members around them. Who will be responsible for the cultivation o the minds and progress of the nation if teachers are prevented from doing what they do best, teaching children. Instead, teachers' efforts could be rewarded and assistance offered for the purposes of writing up the content. Education could also be offered to others so that they may read and cite the findings in the appropriate occasions where sexual policy issues are advanced, and in so doing, everyone may eventually benefit from it.

\section{References}

Blackie, C., Gregg, R., \& Freeth, D. (1998). Promoting health in young people. Nursing Standard, 12, 3946.

Bruess, C. E., \& Greenberg, J. S. (1981). Human sexuality, theory and practice. Belmont: Wadsworth.

Bruess, C. E., \& Greenberg, J. S. (1994). Human sexuality, theory and practice. Madison: WCB Brown \& Benchmark. 
Bruess, C. E., \& Greenberg, J. S. (2004). Sexuality education - changes or status quo? American Journal of Health Education, 35, 338-341.

Donnelly, J. (2003). Health counseling, application and theory. Belmont: Thompson Wadsworth.

Greenberg, J. S., Bruess, C. E., \& Mullen, K. D. (1993). Sexuality, Insights and Issues. Dubuque: WCB Brown and Benchmark.

Kalliopuska, M. (1990). Empatia, tie ihmisyyteen [empathy, road to humanity]. Helsinki: Kirjayhtymä.

Kontula, O., \& Meriläinen, J. (1988). Nuorten kypsyminen seurusteluun ja seksuaalisuuteen [adolescent maturation to courtship and sexuality]. Publications of the National Board of Health-Finland, Health Education, Series Original Reports 9.

Kontula, O., Rimpelä, M., \& Ojanlatva, A. (1992). Sexual knowledge, attitudes, fears and behaviors of adolescents in Finland (the KISS study). Health Education Research, 7:69-77.

Miilumäki, J., \& Sassi, H. (2004). Peruskoulun seksuaalikasvatus - varhaisnuorten silmin [sex education in the eyes of adolescents at basic school]. Department of Teacher Education, University of Turku at Rauma. (Master's Thesis). (Finnish)

Nummelin, R. (2000). Seksuaalikasvatusmateriaalit - pääkaupunkiseutulaisten nuorten näkemyksiä ja kokemuksia [sexuality education material - as viewed and experienced by adolescents in Helsinki region]. Acta Universitatis Tamperensis 778, Tampere. (Doctoral dissertation) (Finnish)

Ojanlatva, A., Rautava, P., Helenius, H., Korkeila, K., Sundell, J., Kivimäki, M., Vahtera, J., Mäkinen, J., \& Koskenvuo, M. (2005). Associations of social support and sex life - the HeSSup study. Patient Education and Counseling, in press.

Ojanlatva, A., Helenius, H., Rautava, P., Ahvenainen, J., \& Koskenvuo, M. (2003). Will childhood relationships with parents contribute to a satisfying sex life? Sexual and Relationship Therapy, 18, 205-214.

Rew, L., \& Horner, S. D. (2003). Youth resilience, framework for reducing health-risk behaviors in adolescence. Journal of Pediatric Nursing, 18(6), 379-388.

Shearer, J. E. (2002). The concept of protection: a dimensional analysis and critique of a theory of protection. Advances in Nursing Science, 25(1), 65-78.

Stuart-Smith, S. (1996). Teenage sex, cognitive immaturity increases the risk. British Medical Journal, 312:390-391.

Van den Bossche, F., \& Rubinson, L. (1998) Contraceptive self-efficacy in adolescents: a comparative study of male and female contraceptive practices. Journal of Sex Education and Therapy, 22(2), 23-29.

\section{Acknowledgments}

The authors wish to acknowledge Tero Vahlberg, MSc. He was consulted regarding appropriate statistical methods to be used with this small sample.

Author Information

Ansa Ojanlatva, PhD, CHES, CSE*

Docent, Health and Sexuality Education,

Department of Teacher Education, and

Institute of Biomedicine

Center for Reproductive and Developmental Medicine

Sanitas 3rd Floor, Lemminkäisenkatu 1

20014 University of Turku/Finland

Ph.: +358-2-333 8513

Fax.: +358-2-333 8439

E-Mail: ansoja@utu.fi 


\author{
Hanna Sassi, MEd \\ Department of Teacher Education \\ University of Turku-Rauma \\ Finland \\ Jutta Miilumäki, MEd \\ Department of Teacher Education \\ University of Turku-Rauma \\ Finland
}

* corresponding author 